\title{
Scaling environmental change through the community-level: a trait-based response-and-effect framework for plants
}

\author{
KATHARINE N. SUDING*, SANDRA LAVOREL $\dagger$, F. S. CHAPIN III $\ddagger$ JOHANNES H. C. \\ CORNELISSEN§, SANDRA DÍAZף, ERIC GARNIER\|, DEBORAH GOLDBERG**, \\ DAVID U. HOOPER $\dagger$, STEPHEN T. JACKSON $\ddagger \ddagger$ and MARIE-LAURE NAVAS§§ \\ ${ }^{*}$ Ecology and Evolutionary Biology, University of California Irvine, Irvine CA 92697-2525, USA, †CNRS Université Joseph Fourier, \\ BP 53 X 38041, Grenoble, Cedex 9, France, †Institute of Arctic Biology, University of Alaska, Fairbanks, AK 99775, USA, \\ $\S$ Department Systems Ecology, Vrije Universiteit, De Boelelaan 1085, 1081 HV Amsterdam, The Netherlands, $\mid$ Instituto \\ Multidisciplinario de Biología Vegetal (CONICET-UNC), and FCEFyN, Universidad Nacional de Córdoba, C. C. 495, 5000 \\ Córdoba, Argentina, \|Centre d'Ecologie Fonctionnelle et Evolutive, UMR 5175, CNRS - 1919, Route de Mende - F 34293 \\ Montpellier, Cedex 5, France, ${ }^{* * E c o l o g y}$ and Evolutionary Biology, 830 N. University, University of Michigan, Ann Arbor, MI, \\ 48109-1048, USA, ††Department of Biology, Western Washington University, Bellingham, WA 98225, USA, ††Department of \\ Botany and Program in Ecology, 1000 E. University Ave., University of Wyoming, Laramie, WY 82071, USA, §§Département des \\ Sciences pour la Protection des Plantes et Ecologie, Ecole Nationale Supérieure Agronomique de Montpellier, 2 Place Viala, 34060 \\ Montpellier, Cedex 1, France
}

\begin{abstract}
Predicting ecosystem responses to global change is a major challenge in ecology. A critical step in that challenge is to understand how changing environmental conditions influence processes across levels of ecological organization. While direct scaling from individual to ecosystem dynamics can lead to robust and mechanistic predictions, new approaches are needed to appropriately translate questions through the community level. Species invasion, loss, and turnover all necessitate this scaling through community processes, but predicting how such changes may influence ecosystem function is notoriously difficult. We suggest that community-level dynamics can be incorporated into scaling predictions using a trait-based response-effect framework that differentiates the community response to environmental change (predicted by response traits) and the effect of that change on ecosystem processes (predicted by effect traits). We develop a response-and-effect functional framework, concentrating on how the relationships among species' response, effect, and abundance can lead to general predictions concerning the magnitude and direction of the influence of environmental change on function. We then detail several key research directions needed to better scale the effects of environmental change through the community level. These include (1) effect and response trait characterization, (2) linkages between response-and-effect traits, (3) the importance of species interactions on trait expression, and (4) incorporation of feedbacks across multiple temporal scales. Increasing rates of extinction and invasion that are modifying communities worldwide make such a research agenda imperative.
\end{abstract}

Keywords: community dynamics, diversity, ecosystem responses, effect and response framework, functional traits, global change, leaf-level scaling, physiology

Received 6 November 2006; revised version received 19 July 2007 and accepted 6 September 2007

Correspondence: Katharine N. Suding, fax +949 824 2181,

e-mail: ksuding@uci.edu

(C) 2008 The Authors

Journal compilation (C) 2008 Blackwell Publishing Ltd
Introduction

Human activities have changed global climate, land cover, and biodiversity at unprecedented rates (Steffen 
et al., 2004). It is reasonable to expect that nearly all ecosystems will experience directional changes in some abiotic and biotic controls, novel combinations of others, and in many cases, feedbacks that could lead to new types of ecosystems. The socioeconomic consequences of global change will depend on how these changes translate into altered ecosystem processes and services (Costanza et al., 1997; Balmford et al., 2002; Millennium Ecosystem Assessment, 2003).

With the unprecedented nature of these changes, science is faced with the challenge of predicting how ecological systems will respond. Predicting future changes based on relationships and patterns in the current environment or in paleoecological records offers one way to address this question. While this approach has yielded important insights, it is largely correlational, making the identification of the roles of specific drivers of change (e.g. climate, atmospheric chemistry, land use, biota) difficult (Osmond et al., 2004). This approach also has limitations because climates in the near future may lack modern or paleo analogs (Williams et al., 2007) and because future change will likely not be incremental and proportional to past change (Clark et al., 2001; Thomas et al., 2004). A complementary approach is to identify the functional or mechanistic basis of the links between ecosystem functioning and global changes by scaling processes (Woodward et al., 1991; Field et al., 1992; Shaver et al., 2000; Currie, 2001; Iverson \& Prasad, 2001). Here, we focus on critical needs in this latter domain.

Some processes scale more easily than others. Changes in the environment can affect ecosystem processes directly through effects on abiotic controls and indirectly through effects on the physiology, morphology, and behavior of individual organisms, the structure of populations, and the composition of communities. While our understanding of how some of these pathways influence ecosystem function is strong, other pathways are less well understood. For example, some physiological processes at the organ or individual level (e.g. photosynthesis, metabolism) scale well to regional and global patterns of ecosystem functioning (e.g. carbon flux) (Field et al., 1992). In contrast, many population and community processes (e.g. recruitment, species interactions, species turnover) do not (Bazzaz, 1993; Chapin et al., 2000; Thompson et al., 2001; McGill et al., 2006). This difficulty in scaling up may arise from an emphasis in community ecology on context specificity - the importance of site, pairwise interactions among species, and history - at the expense of general principles (McGill et al., 2006).
While scaling through the community level remains a challenge, widespread evidence indicates its importance. For example, Grime et al. (2000) found that response to simulated changes in climate depended strongly on the functional characteristics of the community. Across geographic gradients in water availability, net primary production increases much more than predicted based on the response of a given community to interannual fluctuations in precipitation (Lauenroth \& Sala, 1992), due to species turnover along the geographic gradient. Similar patterns occur in response to nitrogen fertilization across moisture gradients (Hooper \& Johnson, 1999). Changes in primary productivity couple poorly with photosynthesis under experimentally warmed conditions in the arctic due to shifts in species composition (Hobbie \& Chapin, 1998). In cases such as these, community-level changes may amplify or dwarf physiological responses, resulting in changes in ecosystem processes that cannot be predicted by the physiology or morphology of individual plants present initially.

Given the sometimes complex interdependencies at the community scale, ecologists will need to emphasize only the critical processes that will aid prediction. While the concern that community dynamics play a large but neglected role in global change predictions has been aired for some time (e.g. Woodward et al., 1991; Bazzaz, 1993), incorporating these dynamics into a generalizable framework has been difficult (Grime, 2006). Functional classification approaches offer a way to achieve such a framework (Grime et al., 1988; Woodward \& Diament, 1991; Gitay \& Noble, 1997). We argue that a trait-based response-and-effect framework (Fig. 1) is a very valuable tool for incorporating community dynamics into predictions of environmental change. By using this framework in the context of environmental change, we apply arguments about scaling through the community level to predict how response-and-effect components of change will affect ecosystem function. We then outline a research agenda to further advance applications of this trait-based scaling approach in global change research.

\section{A response-and-effect framework for scaling from individuals to ecosystems}

The response-and-effect framework for determining how community dynamics will influence ecosystem function involves integrating two components: (1) how a community responds to change, and (2) how that changed community affects ecosystem processes. The approach distinguishes functional response groups 
(a)

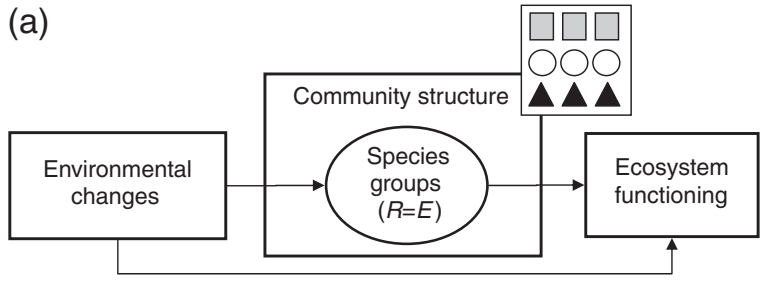

(b)

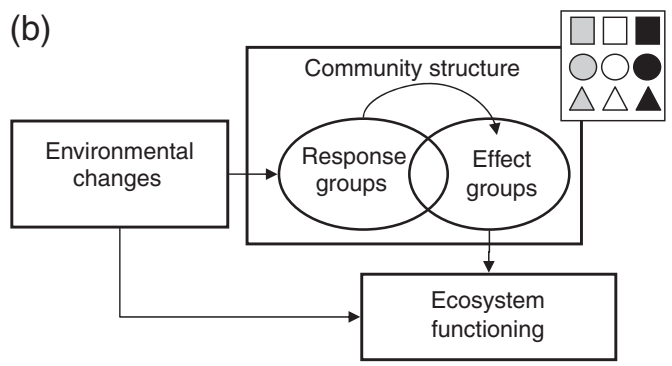

(c)

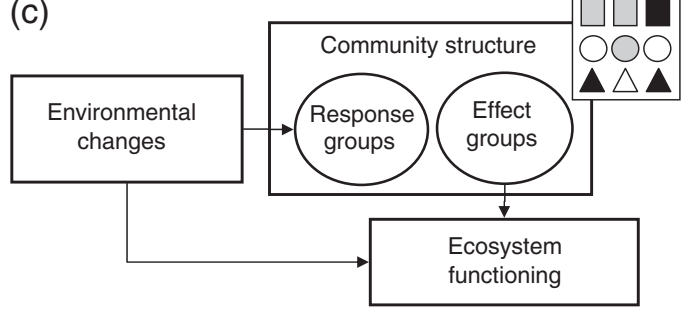

Fig. 1 The response-and-effect framework for scaling through the community level distinguishes between the species (and their functional traits) that respond to environmental change (i.e. response groups, shown as different shapes), and the species and traits that impact ecosystem function (i.e. effect groups, shown as white, gray or black). These two groups may completely overlap (a), reinforcing the effects of environmental change through community dynamics. In other cases, effect groups may be represented by all response groups (b), which may lead to functional resilience to change, or effect groups may be random with respect to response groups (c).

(groups of species ${ }^{1}$ with a similar response to a particular environmental factor such as resource availability, disturbance or $\mathrm{CO}_{2}$ ) and functional effect groups (species that exert similar effects on one or several ecosystem functions). While the distinction between response and effect has been used to describe competitive dynamics for some time, both phenomenologically (Goldberg \& Werner, 1983) and for functional traits

\footnotetext{
${ }^{1}$ Although we discuss functional classification in terms of species and the grouping of species, it also applies to groupings at other levels of organization, such as genotypes or phenotypes of individuals acclimated to different conditions. The issues we address apply to all organisms, although many of the best documented examples (e.g. photosynthesis/carbon-gain relationships) are from plants.
}

(Goldberg, 1990), it has been applied to ecosystem function only recently (Landsberg et al., 1999; Walker et al., 1999; Hooper et al., 2002; Lavorel \& Garnier, 2002; Naeem \& Wright, 2003). Here, we extend this approach to the challenge of scaling processes from individuals to ecosystems through the community level in the context of environmental change.

The use of traits or groupings to predict functional response to environmental change has developed rapidly over the last two decades (Grime et al., 1988; Woodward \& Diament, 1991; Chapin et al., 1993; McIntyre et al., 1995; Gitay \& Noble, 1997; Poff, 1997; Purvis et al., 2000), including bodies of work on traits related to the probability of extinction (e.g. Davies et al., 2000; Cardillo et al., 2005; Williams et al., 2005) and invasion (e.g. Grotkopp et al., 2002; Hamilton et al., 2005; Olden et al., 2006). The community assemblage that will affect ecosystem properties is the result of sorting processes among individuals with appropriate response traits (Weiher et al., 1998; Grime, 2006). These response traits may encompass response to environmental change directly and response through compensatory dynamics due to consequent changes in species interactions. The altered community will impact ecosystem processes via changes in the representation of ecosystem-effect traits. Suites of effect traits are often reliable predictors of ecosystem function (Chapin et al., 1996; Wolters et al., 2000; Díaz \& Cabido, 2001; Garnier et al., 2004) across a wide range of ecosystem types (Grime et al., 1997; Reich et al., 2003; Díaz et al., 2004; Kremen, 2005), and understanding of how traits affect various ecosystem properties is a currently growing area of research. The degree to which individuals with response traits favoured by the changed environment differ in their effect traits compared with the initial assemblage will determine the extent to which community change influences ecosystem function.

Evidence suggests that traits should often differ in their contribution to response or effect functional groupings. For instance, community response to environmental perturbations often depends on traits relating to fecundity, regeneration, and dispersal (Clark et al., 1998; Hubbell, 2001; Higgins et al., 2003; Kneitel \& Miller, 2003; Neilson et al., 2005; Grime, 2006), while these traits themselves are not, in turn, important direct drivers of ecosystem processes. In contrast, functional effect groupings are likely to be based on traits that relate to nutrient recycling and storage (litter chemistry, grazer efficiency, and behavior, biomass allocation). One major trade-off that might affect both response and effect is between attributes that allow rapid acquisition of resources (acquisitive type) and those that maximize conservation of resources (conservative type) for plants (Grime et al., 1997; Díaz et al., 2004; Wright et al., 2004) 
and animals (Arendt, 1997; Schiesari et al., 2006). Traits related to trophic position and body size may also be strongly related to both effect and response (Chalcraft \& Resetarits, 2003; Schmitz, 2004; Larsen et al., 2005). Hence, it is likely that the relationship between effect and response will depend on the particular traits considered. As we detail below, this variation produces several different types of dynamics that will influence how species traits scale to ecosystem functioning.

While traits influence per-capita effects and responses, abundance is also an important translator of response and effect. Clearly, a species that doubles its population size due to an environmental change would be more likely to cause a shift in function if it rose from $30 \%$ to $60 \%$ abundance rather than $3 \%$ to $6 \%$. Abundant species are often more functionally important simply due to greater representation (Grime, 1998; Sugihara et al., 2003; Garnier et al., 2004; Balvanera et al., 2005). While a simple 'mass-ratio' rule applies in many circumstances (Grime, 1998; Garnier et al., 2004; Quested \& Eriksson, 2006), in many cases a species or group has a disproportionate effect on ecosystem function (Power et al., 1996; Lyons et al., 2005). Some functional effects are proportional to abundance, with effect being determined by the most abundant one or two species, whereas in other cases functional effects may not scale as directly with abundance due to nonadditive or higher order interactions.

Thus, at least three factors should be important to predict how environmental change influences ecosystem function through community dynamics: species abundance responses as related by response functional traits; the relationship between response-and-effect functional traits; and the resulting altered representation of effect functional traits. In the next section, we further develop this framework, articulating the roles of these components and highlighting additional assumptions that add complexity to this approach.

\section{Basic scaling approach: response and effect}

Most of the successful approaches that scale from the individual-level to ecosystem processes assume continuous response functions among the environment, plant traits, and ecosystem functioning. This implies that a particular trait or group of traits $(X)$ produces a particular aggregate ecosystem effect $(Y)$, regardless of species identity or community context.

$$
Y=f(X)
$$

While traits are important in the above relationship (e.g. a given environment supports biota that have a given trait distribution and a given effect on ecosystem function), community dynamics are not included. This omission may work if individuals of all species behave similarly or if there is one species that dominates all dynamics. For instance, photosynthesis research has successfully linked molecular patterns with global patterns (Schulze et al., 1994) because light response curves of net photosynthesis of plants acclimated or adapted to different light intensities, with variations in leaf angle and photosynthetic properties, can be translated into carbon fixation by the canopy as a whole (Farquhar \& Sharkey, 1982; Field et al., 1992). If the phenology of leaf carbon gain is taken into account, environmental controls over global primary production are identical to those described for net photosynthesis of individual leaves (Reich et al., 1997). When selection for optimal performance at the level of the individual in a certain environment gives rise to predictable patterns at the ecosystem level, such as for photosynthesis and primary production, there may be little reason to include more complex community dynamics in predictive models. However, these cases may not be widespread. While there have been few explicit tests of when or to what extent the inclusion of community dynamics may fundamentally alter model predictions, recent evidence (e.g. Grime $\mathrm{et}$ al., 2000; Joel et al., 2001; Henry et al., 2005) suggests that community-level changes are likely to affect ecosystem processes in ways that cannot be predicted by the physiology or morphology of individual plants.

To incorporate community dynamics, we begin by aggregating all species or groups in the community. This in itself is not simple; here we assume that species contributions are additive, following the framework of Balvanera et al. (2005). We define the current contribution of a given species (or genotype or group of species), $j$, to an ecosystem process, $Y$, at time 1 as $C_{j 1}$. Thus, the ecosystem function carried out by the initial community (i.e. before a change in the environment) is

$$
Y_{1}=\sum_{j=1}^{s} C_{j 1}
$$

According to the mass-ratio hypothesis (Grime, 1998), which proposes that the controls on function are in proportion to productivity or abundance, the current functional contribution of a species, $C_{j 1}$, can be broken down in terms of the per-gram or per-capita effect of a species on $Y\left(E_{j 1}\right)$ and its current abundance $\left(n_{j 1}\right)$.

$$
Y_{1}=\sum_{j=1}^{s}\left(n_{j 1} \times E_{j 1}\right)
$$

Thus, we assume that ecosystem functions are determined by the summed traits of the dominant species 
and are relatively insensitive to the traits and trait diversity of the subordinates. Most tests indicate that the effects of certain functional types or attribute combinations on ecosystem processes are often proportional to their local abundance (Hobbie, 1992; Díaz \& Cabido, 2001; Garnier et al., 2004), although there are also welldocumented cases of species with effects disproportionate to their productivity or abundance. In most of these cases, the species have unique traits that modify or create habitat for other species (Lill \& Marquis, 2003; Wright \& Jones, 2004) or traits that contribute to a function that depends on relative trait diversity (i.e. resource partitioning) rather than absolute values (Lyons et al., 2005). We suggest ways to incorporate these alternatives in the following section (Question 3, below).

Determining per-capita species effects and their relationship to traits is tractable. Species contributions to ecosystem processes $\left(E_{j}\right)$ should relate the effect (e.g. a process measurement such as $\mathrm{N}$ cycling or $\mathrm{C}$ storage) of a certain species or group of species to particular traits (e.g. an effect trait such as relative growth rate or wood density). Several different experimental approaches can achieve this goal, including trait and ecosystem measurements of mixed-species systems in the field (Garnier et al., 2004; Wright et al., 2004; Quétier et al., 2007), planted monocultures (Reich et al., 2001; Craine et al., 2002; Engelhardt, 2006), and removal or invasion experiments (Díaz et al., 2003; Bret-Harte et al., 2004). Ultimately, all approaches break down $E_{j}$ into functions describing a process (e.g. decomposition rate) and how that process is affected by a measurable trait (e.g. lignin concentration). There are several challenges associated with this step that will be fruitful avenues of research; we outline these in the following section (Questions 1, 2, below).

We can also use a trait-based prediction of response to a changed environment $(t=2)$ where $n_{j 2}$, the abundance of species $j$ in the new environment, is

$$
n_{j 2}=n_{j 1} \times R_{j} .
$$

Response $\left(R_{j}\right)$ includes both the direct response to the environmental change and any compensatory dynamics following the perturbation due to changes in species interactions. In reality, different response traits could be predictive of these two types of response and thus necessitate separation into two or more components (e.g. Manning et al., 2006). In addition, this basic framework assumes that changes occur simultaneously, although feedbacks and time lags can affect the time course of responses (we suggest ways to incorporate temporal variation in Question 4, below).
Several different approaches could be used to estimate response, $R_{j}$, to a change, as well as the traits related to that response. These approaches include spatial distribution along environmental gradients (Díaz \& Cabido, 1997; De Bello et al., 2005), temporal changes in the paleorecord (Jackson \& Overpeck, 2000), or experimental manipulations (e.g. Joel et al., 2001; Reich et al., 2001). While we show response in terms of abundance, it could also reflect presence or absence such as the probability of local extinctions or invasions (e.g. Larsen et al., 2005). One challenge, however, is that the responses of particular species could differ depending on community composition. We expand on this challenge in the following section (Question 3, below).

To predict future ecosystem functioning, the contribution of a given species, $j$, to future aggregate ecosystem function, $Y_{2}$, can be assumed to be function of the effect of a species on $Y$ and its predicted abundance $n_{2}$ [similar to Eqn (3)]. Substituting the response relationship [Eqn (4)] for $n_{2}$, the future ecosystem function can be estimated as

$$
\Upsilon_{2}=\sum_{j=1}^{s} f\left(n_{j 1} \times R_{j}, E_{j}\right) .
$$

Clearly, this relationship differs from the single trait-environment relationship [Eqn (1)] in many ways. Incorporating several species or species groups into predictions of ecosystem function not only adds the challenge of aggregating multiple entities, but also the challenges of assessing effects and responses for several species or groups and explicitly incorporating changes in abundance. While the resulting formulation is still very basic, a major conclusion of this approach is that a particular environmental change does not have to give rise to the same suite of species traits and therefore the same ecosystem functioning.

\section{Applying the effect-and-response framework: a research agenda}

The effect and response framework above indicates that the relationship between effect, response, and abundance will strongly influence predictions of ecosystem function. While the framework lays a basic foundation for scaling through the community level, progress in several key research areas would aid its widespread application. In this section, we address how the effectand-response framework can be implemented and then expanded to cover more complex and realistic processes. Below, we focus on advancing four major research themes necessary to apply this framework: functional trait classification, response-effect trait linkages, community context and indirect effects on 
species trait classifications, and feedbacks across multiple temporal scales.

Question 1: How reliably can we identify response traits that successfully predict species responses to key global changes? Likewise, how reliably can we identify which functional effect traits are relevant for a given ecosystem property? The power of the response-effect framework will be limited by the extent to which we can identify relevant response-and-effect traits [indicative of $E$ and $R$ in Eqns (3) and (4)]. While improving trait classifications has been a research goal for at least a decade (Noble \& Gitay, 1996; Gitay \& Noble, 1997; Grime et al., 1997; Lavorel et al., 1997; Weiher et al., 1999; Craine et al., 2002; Wright et al., 2004), this remains a necessary step forward. Some species are well-studied, both in terms of their responses to key global change drivers and their effects on important ecosystem processes, but most species remain unmeasured. In one of the few empirical tests that used response-and-effect traits to predict consequences of environmental change, Engelhardt (2006) successfully identified traits in monocultures that were related to both effect and response. Whether these traits would have been identifiable in species mixtures in field settings is unclear, but it confirms the possibility of identifying traits that can predict response to key global changes and their subsequent effect on critical ecosystem properties. In a field-based study, Quétier et al. (2007) determined traits that linked changes in soil resource availability (due to fertilization) and disturbance regimes (grazing, mowing) to changed ecosystem properties in managed subalpine grasslands. Comparative trait ecology is a very active area of research, and further progress such as these studies will be fundamental to lay the foundation of a predictive framework.

Although we expect species-level trait screening to form the backbone of future advances in this area (e.g. Williams et al., 2005; Díaz et al., 2007; Quétier et al., 2007), several other trait-based approaches are extremely promising. Comparative approaches informed by phylogeny offer a powerful tool for understanding the long-term role of particular traits in ecological interactions (Ackerly, 2003; Cavender-Bares et al., 2004). Analyses that incorporate trait variation within and among species (Cornwell et al., 2006; Ackerly \& Cornwell, 2007) and niche overlap (Mouillot et al., 2005) are also proving to be powerful approaches.

Functional classification also applies to groupings at other levels of organization, such as genotypes or phenotypes of individuals acclimated to different conditions. The challenge of trait characterization is ultimately at the phenotypic level; the average characteristics of a species could simplify this task if trait differences among conspecific individuals are less than differences among species. However, we know that some traits are highly variable within species and that environmental changes can cause shifts in abundance of different genotypes and phenotypes (Rehfeldt et al., 1999; Whitham et al., 2003; Mondor et al., 2005). For example, some leaf chemical components are more variable within a species than among species due to strong environmental controls (Grimshaw \& Allen, 1987). In such cases, aggregation of species using the mean of all individuals within a species is not appropriate. In addition, Wright et al. (2006) found that classification schemes based on some traits widelyassumed to be important (e.g. N-fixer, forb, grass) are no better than random groupings, suggesting the need to question traditional morphotype classifications and screen for effect classifications that link directly to ecosystem-level mechanisms.

Question 2: What linkages exist between effect-and-response traits and what are the consequences for ecosystem function? Evidence indicates that the response of ecosystem patterns and processes to environmental change is rarely linear (Ackerly \& Bazzaz, 1995; Mayer \& Rietkerk, 2004; Groffman et al., 2006): a small change in the environment can lead to rapid and large changes in structure and function. The relationship between response-and-effect groups as a system undergoes change is one factor that can contribute to nonlinear relationships. How often are response and effect strongly correlated with one another? Are particular systems characterized by strongly correlated responseand-effect groups? Can we use the ideas of a uniform distribution of response-and-effect traits to aid resilience in management?

In our view, an important research focus is to explicitly investigate response-effect linkages relevant to key global changes in different ecosystems. Understanding the relationship between response-and-effect trait groups may help predict the occurrence and pattern of nonlinear response of ecosystem function to environmental change. To illustrate, we evaluate the ramifications of three types of relationships: perfect correlation (a response group is an effect group), completely overlapping distribution (every response group contains every effect group) and random distribution (no consistent relationship between effect-and-response) (Figs 1 and 2).

If effect-and-response are correlated or if important effect traits and response traits are the same $(E=R)$, then we would expect to see nonlinear changes in ecosystem function due to a changing environment (Fig. 2a and b). For instance, in cases where functionally important effect groups are also the most extinction prone (i.e. have a negative response), we would expect particularly rapid losses of function; this results in a negative correlation of effect-and-response traits (Fig. 
2a). For example, Larsen et al. (2005) found that female body size of bees was both a response-and-effect trait because it was positively related to the probability of extinction due to agricultural intensification (response) and to pollination efficiencies (effect), leading to a strong decline in pollination function due to agricultural intensification (Fig. 3). Engelhardt (2006) found that root growth can be used simultaneously to predict the response of aquatic macrophytes to flooding, as well as their effects on sediment nutrient dynamics, suggesting potentially strong consequences of disturbance on water quality. Bunker et al. (2005) simulated a possible extinction scenario in a tropical forest plot of Barro Colorado Island, Panama, where the key response trait and key effect trait were both wood density (high wood density species were more extinction prone and contributed most to carbon storage). They found the loss of these high-density wood species would lead to a $70 \%$ decrease in carbon storage, while random loss of species would lead to just a $4 \%$ loss of carbon storage. Similarly,
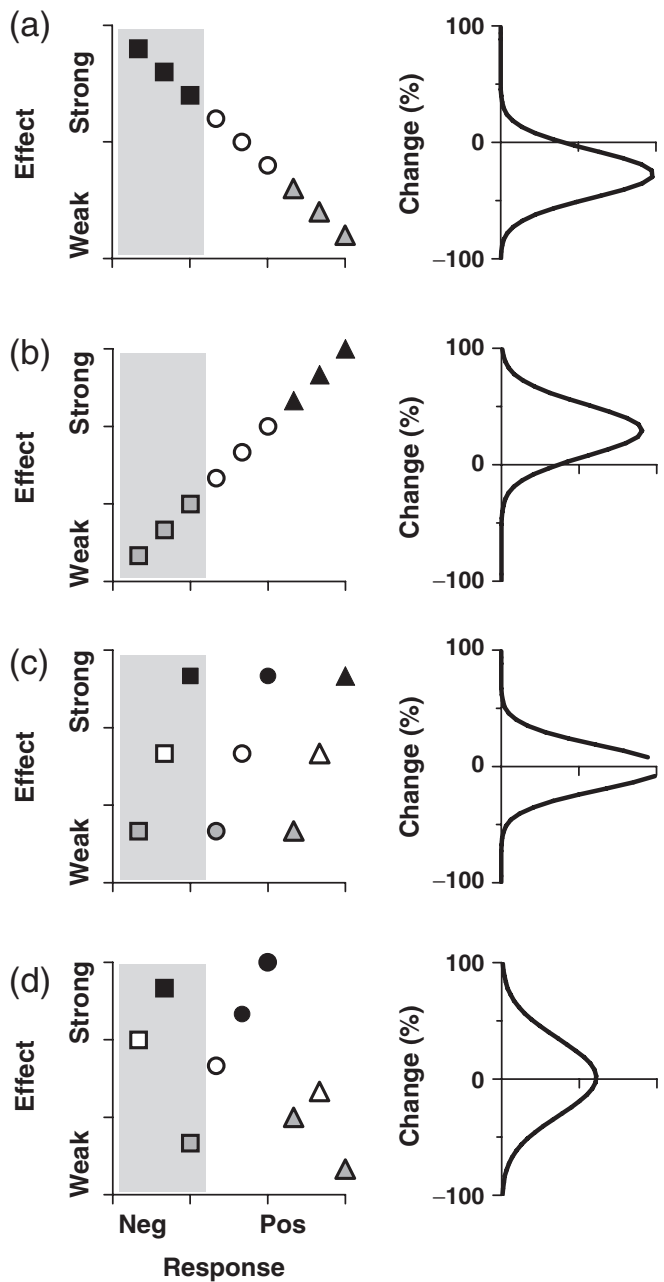

when Solan et al. (2004) simulated the loss of large marine invertebrates, in which body size was positively related to both extinction risk (response) and per-capita effect of biogenic mixing depth (effect), they found that the effect of bioturbation changed more rapidly than in random extinction scenarios. In addition, they found that compensation by the remaining species, while possible when responses were not related to effect, did not mitigate the losses when effect-and-response traits were correlated because the remaining species were small and could not offset the functions performed by the missing large species.

The above examples all deal with negative correlations among effect-and-response traits; positive correlations between response-and-effect traits are also possible (Fig. 2b). While still nonlinear, a change in community structure would result in less change in ecosystem function than expected if effects and responses were not associated. This relationship could occur, for instance, when traits related to negative response (e.g. more extinction prone, more likely to decrease in abundance) are associated with traits contributing a weaker effect (e.g. less carbon storage). In this case, the response in terms of extinctions would result in less change in ecosystem function relative to random extinctions. Note, the direction of effects and

Fig. 2 Possible outcomes due to differing relationships between effect and response traits: effect and response could be perfectly correlated [either negatively (a) or positively (b)], overlapping (c), or random (no relationship, d). To avoid valuing ecosystem functions, we express effect in terms of its magnitude (i.e. from weak to strong) on function. Responses are expressed as positive or negative changes due to the environmental change. Symbols are species. In all scenarios, we simulated the loss of the three species with the most negative responses (i.e. decrease in abundance, most at risk of extinction) due to a particular environmental change; these species are in the region of the graph highlighted in gray. We conducted a series of simple simulations to estimate effects of loss of these three species. In the initial nine-species community, abundances were log-normally distributed and independent of effect or response ranking. Change in ecosystem function (right column) was estimated as the difference in the product of effect and relative abundance [Eqn (3)] before and following the loss of the three species. Fifty permutations were run, each with abundance randomly assigned, to estimate the distribution of change expected in each scenario. The scenario with no relationship between effect and response reflects the results of 200 permutations where effect, response, and abundance were all randomized with respect to one another. While scenarios $a$ and $b$ predict a change in ecosystem function, scenarios $\mathrm{c}$ and $\mathrm{d}$, on average, do not. Instead, these last two scenerios differ in the variability of possible effects, with consistent resilience to change in scenario (c) and wide effects in both directions more likely in scenario (d). 
(a)
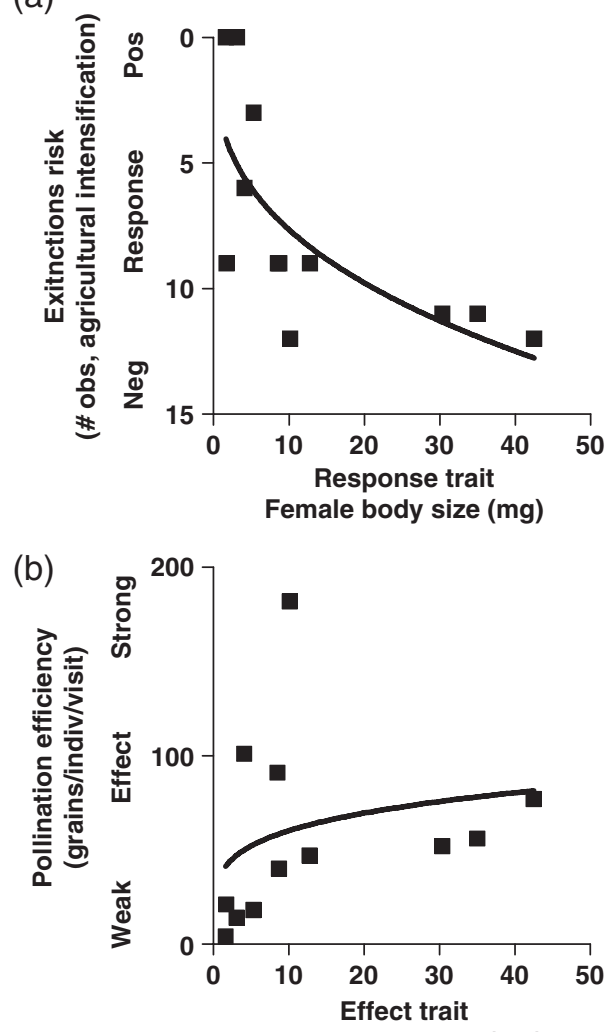

(c)

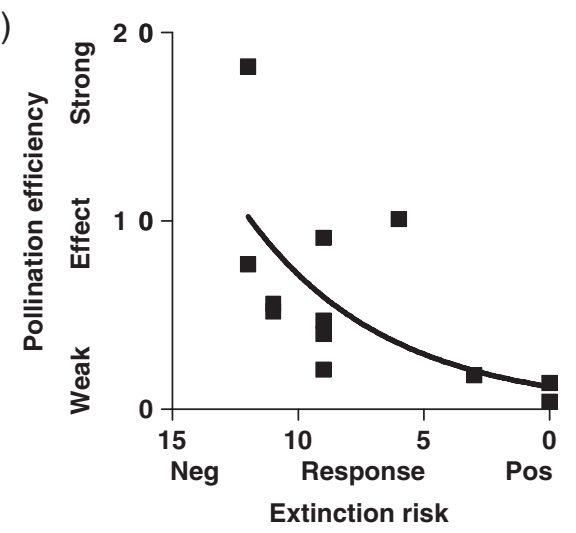

Fig. 3 An example where response and effect traits are the same (Fig. 2a), which could lead to rapid loss of function (from Larsen et al., 2005). Mean body mass of bees (response trait) is correlated with the extinction risk of bees in response to agricultural intensification (response) $(P=0.0009)$ (a). Abundance was not related to extinction risk. Pollination efficiencies (effect) were also weakly correlated with body mass $(P=0.07)(b)$, and so body mass can be considered both a response and effect trait. There was a significant relationship between extinction risk (response) and functional efficiency (effect) $(P=0.012)(\mathrm{c})$, leading to the situation where large bees, more apt to be lost to agricultural intensification, were functionally more efficient in terms of pollination services. Thus, ecosystem function would be predicted to decline due to agricultural intensification (scenario a in Fig. 2). For comparison with Figs 2 and 4, note the reversal of the extinction risk axis in panels (a) and (c). responses will depend on the type of response (e.g. increased probability of extinction but decreased population growth rates) and valuation of effect (e.g. whether more or less carbon storage constitutes a larger effect). Regardless of the direction of effect-response correlation, we expect changes in function that do not mirror the incremental change in environment in systems where effect and response are correlated.

If the distribution of effect and response completely overlaps (every response group contains species of every effect group), then we would expect to see resilience or dampened changes in ecosystem function (Fig. 2c). This scenario is based on the concept of response diversity, when species that contribute similarly to ecosystem function differ in their responses to environmental change (Hooper et al., 2002; Elmqvist et al., 2003; Nystrom, 2006). While average expected change in ecosystem function would be small, this scenario differs from a completely random trait relationship in that it also dampens the potential variability in response (Fig. 2). Several studies support this prediction. In Australian rangelands, Walker et al. (1999) found that grazing caused many of the abundant species to decrease and minor species to increase in abundance. They predicted little change in many ecosystem functions (carbon storage, nitrogen cycling), however, because both increaser and decreaser species were functionally similar with respect to biogeochemistry. Likewise, in California serpentine grasslands, two functionally similar species had opposite responses to rainfall: Plantago erecta increased but Lasthenia californica decreased in low-rainfall years (Hobbs \& Mooney, 1991). While these responses are possibly due to differences in reproductive strategies (Hobbs \& Mooney, 1985), if both forbs contributed similarly to production, the functioning of the system would remain relatively constant through time. In arctic tundra, species' responses to temperature change are well-distributed among the dominant plant morphotypes (evergreen shrubs, deciduous shrubs, forbs, and sedges) (Chapin et al., 1996). Because all of the dominant morphotypes should thus persist under projected warming scenarios, functional effect changes would be less severe than expected without this across-group distribution of functional response types. As a last example, Forys \& Allen (2002) studied vertebrate species turnover in Southern Florida due to European colonization. Although nonnative species replaced many native faunal species, this turnover did not affect body mass distributions (a proxy for function).

A third scenario, where response is random with respect to effect on ecosystem function, may result in ecosystem change roughly proportional to environmental change (i.e. linear responses). For example, the response 
groups tolerant to fire (e.g. species that have traits such as soil seed banks, thick bark, and resprouting capacity) and the effect groups that promote ecosystem flammability (e.g. species that have traits such as high volatile production, low tissue moisture, and retention of dead branches) show little direct overlap (Lavorel \& Garnier, 2002). In Minnesota grasslands, aboveground nitrogen tissue content best predicted plant response to elevated $\mathrm{CO}_{2}$. However, total biomass in monoculture more closely predicted soil nitrogen availability under elevated $\mathrm{CO}_{2}$ conditions (Reich et al., 2001). Thus, although they were able to identify a trait predictive of response (tissue nitrogen content) and a trait predictive of effect (total biomass), these did not help predict effects of $\mathrm{CO}_{2}$ because the two traits were not correlated (Fig. 4). When the traits that determine community response are not closely related to ones that contribute to how vegetation change influences ecosystem processes, we expect change to occur in a stepwise fashion that would approximate linearity over longer-time scales.

While the limited work to date appears to indicate that linkages between effect-and-response traits have important consequences for environmental change, there have been no studies that have explicitly tested how these linkages translate to ecosystem function. We do not know how often each of these types of correlations occurs, or what situations or habitats may be particularly prone to a particular scenario of trait linkage. These research directions could improve our ability to generalize how different trait relationships relate to the response of ecosystems to global change.

Question 3: What are particularly strong and common pathways by which community context and indirect effects influence pathways of community change?

In our basic framework, we assumed that community change results from a variety of independent species responding to environmental change and that their effects do not depend on the identity or traits of the other species present. If so, we expect predictable shifts in community composition based on the sum of independent species responses to a given perturbation. We would also expect predictable effects on ecosystem function based on the direct additive effects of traits on function. However, when interactions (e.g. predation, pollinator limitations, competitive hierarchies, microbial priming) are strong, species responses to environmental change are often contingent on whether they are alone or in multi-species mixtures; we refer to such contingency as 'nonadditivity.' This dilemma complicates the application of the effect-and-response framework because it indicates that $R$ and $E$ for a species can vary depending on context. How often and under what conditions can independent species responses be assumed? Are there some systems where species inter- (a)

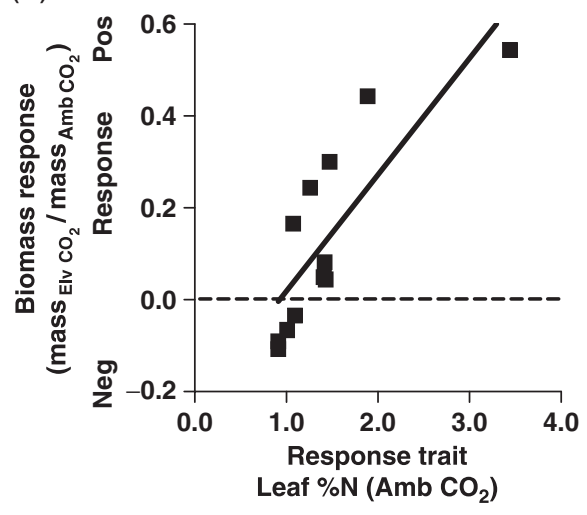

(b)

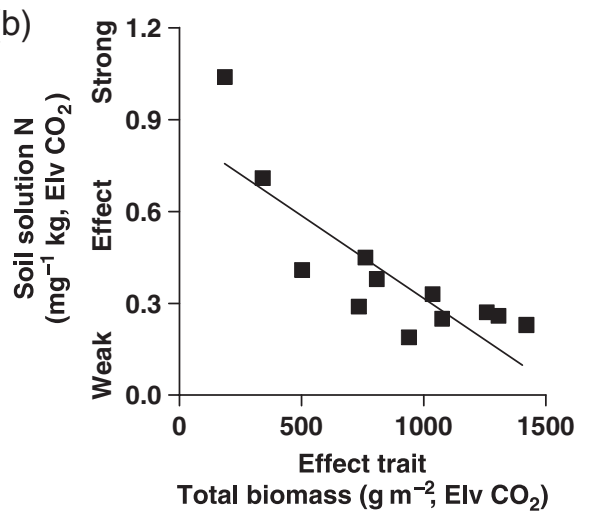

(c)

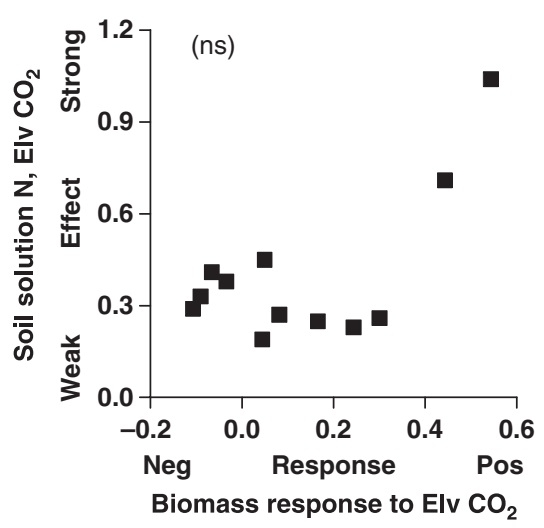

Fig. 4 An example where response and effect traits are not the same nor tightly related to one another (from Reich et al., 2001), as in Fig. 2d. While aboveground nitrogen tissue concentration (response trait) best predicted plant response to elevated $\mathrm{CO}_{2}$ $(P<0.005)$ (a), total biomass (effect trait) more closely predicted soil nitrogen (effect) under elevated $\mathrm{CO}_{2}$ conditions $(P<0.005)$ (b). Although traits (nitrogen tissue content, total biomass) were predictive of response and effect, respectively, they were only weakly correlated with each other $(P=0.02)$. Consequently, there was no relationship between response (plant biomass response to $\mathrm{CO}_{2}$ ) and effect (soil nitrogen at elevated $\mathrm{CO}_{2}$ ) (c). Nitrogenfixing forbs were dropped from these relationships, due to their functional contribution via symbiosis. These results were from experimental monocultures, excluding the role of compensation and nonadditive effects of species interactions in mixtures. 
actions and context-dependency play a relatively minor role in overall response? When nonadditive effects are important, how can they be incorporated into model development? Are there particularly common or important traits (e.g. body size for animals) that can serve as general rules in absence of detailed understanding of all the contingencies and indirect interactions that may lead to nonadditive effects?

Work to date indicates that nonadditivity should be considered the rule rather than the exception, as outcomes are often contingent on combinations of interacting species (Agrawal et al., 2007). For instance, competitive interactions change predictions of species responses to elevated $\mathrm{CO}_{2}$ (Leadley et al., 1999; Joel et al., 2001); most species respond positively to elevated $\mathrm{CO}_{2}$ when grown alone (Korner, 2000), but the presence of other species significantly alters individual outcomes (Poorter \& Navas, 2003). The effects of elevated $\mathrm{CO}_{2}$ on herbivores in mixed-stands couples poorly with individual herbivore-plant responses from single-species experiments (Díaz, 1995; Díaz et al., 1998). Warming and nitrogen addition experiments show the same patterns (Woodward, 1992; Hooper \& Johnson, 1999; Bret-Harte et al., 2004; Klanderud, 2005). Traits that predict the direct response of a group to environmental change could be very different from the traits that influence species interactions (Manning et al., 2006). For example, Henry et al. (2005) found enhanced $\mathrm{CO}_{2}$ increased lignocellulose in all plants but that these increases were counteracted by an increase in the relative biomass of forbs, which contained less ligno-cellulose than grasses. Consequently, due to community-level changes, they found no net change in the overall ligno-cellulose content of senesced tissue under elevated $\mathrm{CO}_{2}$. This evidence suggests it is critical to understand differential responses of component species and how these differential responses affect species interactions with one another and with the environment (Joel et al., 2001; Lee et al., 2003; Schmitz et al., 2003).

While ecological context may be at the heart of accurately scaling through the community-level, our ability to generalize in this area is currently limited. Compensatory responses are notoriously contingent on composition and history. Traits predictive of competitive ability (Tilman, 1982; Goldberg, 1996), response to herbivory (Díaz et al., 2001; Wardle et al., 2003b), strengths of trophic interactions (van der Putten et al., 2004) and even symbiotic associations (Cornelissen et al., 2001) are sometimes found, but generalities are often not sought across systems. Different ecosystems may be dominated by different suites of interactions, such as facilitative associations (Bruno et al., 2003), indirect interactions (Wootton, 2002; Bardgett \& Wardle, 2003), and nontrophic interactions such as ecosystem engineering (Lill \& Marquis, 2003; Wright \& Jones, 2004). Species interactions also change along environmental gradients and the importance of different types of interactions is likely to change as well (Oesterheld, 1992; Wilson \& Tilman, 1993; Fraser \& Grime, 1999; Waide et al., 1999; Pennings et al., 2001; Pugnaire \& Luque, 2001). As yet, we have no recognized suite of predictors for such changes.

To move forward on this issue, we must take a multifaceted, integrated approach to understanding the major pathways by which differential species responses affect species interactions. We are now poised to make substantial progress by asking not only whether a particular factor changes species interactions, but to quantify the relative magnitude of such changes. More studies are simultaneously addressing the importance of different types of interactions (Lambrinos, 2002; Morris et al., 2007), as well as testing how these interactions vary across environmental gradients (Callaway et al., 2002). With this knowledge, it will be easier to identify traits that may be important to quantify in a particular community context.

Recent studies on the role of functional diversity (e.g. Kremen, 2005; Petchey \& Gaston, 2006) form an excellent springboard for understanding contingencies in ecosystem effects due to different combinations of species. Strong evidence indicates that the relative combination of species traits (functional and taxonomic diversity) can influence ecosystem function (Petchey \& Gaston, 2002; Naeem \& Wright, 2003). Recent findings about the relative roles of diversity and abundance indicate that both factors are important in determining ecosystem processes (Fargione et al., 2003; Symstad et al., 2003; Smith et al., 2004; Hooper et al., 2005). The relative, rather then absolute, importance of many species attributes, such as rooting depth and canopy structure, can determine how efficiently the system as a whole utilizes resources because niche differentiation both enhances species coexistence through reduced interspecific competition (i.e. niche complementarity) and allows a fuller use of locally available resources (Wardle \& Peltzer, 2003; Hooper et al., 2005). For instance, Jonsson et al. (2002) found that progressive loss of stream invertebrate species causes a greater than expected loss in leaf-shredding function due to rapid loss of interspecific facilitation of overall rates of shredding. Nonadditive effects of litter mixing cause decomposition of whole communities to scale poorly with the decomposition rates of species in isolation (Wardle et al., 2003a). Petchey \& Gaston (2002) found that complementarity in functional attributes led to rapid loss of functional diversity for simulated extinction scenarios in six plant and animal communities. While the mass-ratio approach is a robust first step in aggregating 
function, explicit comparisons of the similarity and dissimilarity among species (Walker et al., 1999) will greatly improve predictions of aggregated resource use or ecosystem function patterns.

Question 4: What is the time scale over which the incorporation of community processes is important? In our basic framework, we assume that changes occur simultaneously, but there is strong evidence that community dynamics can both delay and accelerate predicted changes. While ecosystem responses to environmental change are likely to be initially dominated by changes in plant physiology and morphology, changes in relative dominance and abundance of species are likely to have important ecosystem influences at longer timescales (Lauenroth \& Sala, 1992; Knapp \& Smith, 2001; Wilson \& Tilman, 2002). Some species may appear to be resilient to change due to their longevity, reducing opportunities for species turnover at the regeneration or recruitment stages until after mortality-causing disturbance (Grime, 1998; Epstein et al., 2004; van Nes \& Scheffer, 2004). This resistance can reduce the magnitude or variability predicted by models that do not take into account dynamics of species turnover (Epstein et al., 2004). Lodgepole pine, for example, is predicted to expand at its northern limits due to climate changes (Johnstone \& Chapin, 2003). However, the pine's expansion may lag behind climate change, due to its dependencies on fire for recruitment into new environments. Alternatively, species turnover due to rapid invasions or local extinctions could increase the magnitude or variance often predicted by models ( $\mathrm{D}^{\prime}$ Antonio \& Kark, 2002; Levine et al., 2003; Larsen et al., 2005). Species turnover can also depend on temporal variation in environment, with establishment accelerated by prior severe disturbance (e.g. drought) and limited to transient favorable periods (Swetnam \& Betancourt, 1998; Lyford et al., 2003; Booth et al., 2005; Gray et al., 2006). Founder or priority effects can also lead to bifurcation in community dynamics, and consequently have longlasting effects on ecosystem functioning (Jenkins \& Buikema, 1998; Corbin \& D'Antonio, 2004; Daehler \& Goergen, 2005; Gamarra et al., 2005). These trajectories of change could facilitate different assembly dynamics and the development of alternative states (Belyea \& Lancaster, 1999; Ackerly, 2003).

Strong plant-soil or above-belowground feedbacks can also influence how community dynamics contribute to ecosystem function over time (van der Putten et al., 2004; Wardle et al., 2004). Species effects can create feedbacks that either buffer or accelerate community change (D'Antonio \& Vitousek, 1992; Hobbie, 1992). For instance, a change in temperature or moisture, predicted to change resource cycling and community composition, may not have as large an effect as predicted because species can counteract a portion of the change through effects on microbial processes (such as nutrient immobilization) or luxury nutrient uptake. The potential for feedback loops exists where plant responses to an environmental change alter resource supply rates or disturbance regimes, which then regulate species responses to subsequent climate change (van der Putten et al., 2004). For example, if an environmental change enhances the success of a species with nitrogen-fixing symbionts, then further responses will be a function of both the external driver and the increased nitrogen availability in the system (Vitousek et al., 2002). Problematic exotic species often exert large effects on ecosystem functioning, which in turn enhance their success through positive feedbacks (Levine et al., 2003). For instance, because exotic grasses invaded Hawaiian woodland in the 1960s, there has been a 35-fold increase in the area burned by fire and a three-fold increase in fire frequency, which in turn favors the expansion of grasslands (D'Antonio et al., 2000). It is critical to know how often feedbacks such as these need to be incorporated into scaling predictions, as they can amplify any direct response several fold.

\section{Conclusions}

While the incorporation of community-level change into models of how global change influences ecosystem function is in its infancy, recent progress suggests that scaling through the community level might greatly improve our predictive capability. Attention to community organization, particularly functional dynamics related to species turnover and biotic interactions, will allow us to make vital advances.

A functional response-and-effect framework can be a powerful new way to scale change through community dynamics. As a starting point, we demonstrate how the relationships among species response, effect, and abundance can lead to general predictions concerning the magnitude and direction of environmental change effects on function. Many uncertainties remain, including how best to quantify effect-and-response traits, the importance of the relationship between responseand-effect, the influence of community context and nonadditive species interactions on trait classification, and incorporation of feedbacks across multiple temporal scales. While all of these research areas will advance the general framework, they also need to be carefully evaluated in terms of their value to predictive capacity at the expense of unneeded complexity. Despite the challenges this research agenda presents, the importance of understanding and managing species invasions, extinctions, and large changes in species composition in nearly every major ecosystem should 
make community-centered scaling a strong research priority in ecology.

\section{Acknowledgements}

This paper is a product of a workshop in Missillac, France, hosted by the W. A. Beling Family and funded by the Albert and Elaine Borchard Foundation. K. N. S. also acknowledges support from US Department of Energy's Program in Ecosystem Research. We thank S. Berry, C. deMazancourt and M. Goulden for useful discussion and comments, E. Hayes for logistical support, and two anonymous reviewers for comments on previous versions of the manuscript.

\section{References}

Ackerly DD (2003) Community assembly, niche conservatism, and adaptive evolution in changing environments. International Journal of Plant Sciences, 164, S165-S184.

Ackerly DD, Bazzaz FA (1995) Plant-growth and reproduction along $\mathrm{CO}_{2}$ gradients - nonlinear responses and implications for community change. Global Change Biology, 1, 199-207.

Ackerly DD, Cornwell WK (2007) A trait-based approach to community assembly: partitioning of species trait values into within- and among-community components. Ecology Letters, 10, 135-145.

Agrawal AA, Ackerly D, Adler F et al. (2007) Filling key gaps in population and community ecology. Frontiers in Ecology and the Environment, 5, 145-152.

Arendt JD (1997) Adaptive intrinsic growth rates: an integration across taxa. The Quarterly Review of Biology, 72, 149-177.

Balmford A, Bruner A, Cooper P et al. (2002) Ecology - economic reasons for conserving wild nature. Science, 297, 950-953.

Balvanera P, Kremen C, Martinez-Ramos M (2005) Applying community structure analysis to ecosystem function: examples from pollination and carbon storage. Ecological Applications, 15, 360-375.

Bardgett RD, Wardle DA (2003) Herbivore-mediated linkages between aboveground and belowground communities. Ecology, 84, 2258-2268.

Bazzaz FA (1993) Scaling in biological systems: population and community perspectives. In: Scaling Physiological Processes: Leaf to Globe (eds Ehleringer JR, Field CB), pp. 233-254. Academic Press Inc., New York.

Belyea LR, Lancaster J (1999) Assembly rules within a contingent ecology. Oikos, 86, 402-416.

Booth RK, Jackson ST, Forman SL, Kutzbach JE, Bettis EA, Kreig J, Wright DK (2005) A severe centennial-scale drought in midcontinental North America 4200 years ago and apparent global linkages. Holocene, 15, 321-328.

Bret-Harte MS, Garcia EA, Sacre VM, Whorley JR, Wagner JL, Lippert SC, Chapin FS (2004) Plant and soil responses to neighbour removal and fertilization in Alaskan tussock tundra. Journal of Ecology, 92, 635-647.

Bruno JF, Stachowicz JJ, Bertness MD (2003) Inclusion of facilitation into ecological theory. Trends in Ecology \& Evolution, 18, 119-125.
Bunker DE, DeClerck F, Bradford JC et al. (2005) Species loss and aboveground carbon storage in a tropical forest. Science, 310, 1029-1031.

Callaway RM, Brooker RW, Choler P et al. (2002) Positive interactions among alpine plants increase with stress. Nature, 417, 844-848.

Cardillo M, Mace GM, Jones KE et al. (2005) Multiple causes of high extinction risk in large mammal species. Science, 309, 1239-1241.

Cavender-Bares J, Ackerly DA, Baum D et al. (2004) Phylogenetic overdispersion in Floridian oak communities. American Naturalist, 163, 823-843.

Chalcraft DR, Resetarits WJ (2003) Predator identity and ecological impacts: functional redundancy or functional diversity? Ecology, 84, 2407-2418.

Chapin FS, Autumn K, Pugnaire F (1993) Evolution of suites of traits in response to environmental-stress. American Naturalist, 142, S78-S92.

Chapin FS, Bret-Harte MS, Hobbie SE, Zhong HL (1996) Plant functional types as predictors of transient responses of arctic vegetation to global change. Journal of Vegetation Science, 7, 347-358.

Chapin FS, Zavaleta ES, Eviner VT et al. (2000) Consequences of changing biodiversity. Nature, 405, 234-242.

Clark JS, Carpenter SR, Barber M et al. (2001) Ecological forecasts: an emerging imperative. Science, 293, 657-660.

Clark JS, Macklin E, Wood L (1998) Stages and spatial scales of recruitment limitation in southern Appalachian forests. Ecological Monographs, 68, 213-235.

Corbin JD, D'Antonio CM (2004) Competition between native perennial and exotic annual grasses: implications for an historical invasion. Ecology, 85, 1273-1283.

Cornelissen JHC, Aerts R, Cerabolini B, Werger MJA, van der Heijden MGA (2001) Carbon cycling traits of plant species are linked with mycorrhizal strategy. Oecologia, 129, 611-619.

Cornwell WK, Schwilk DW, Ackerly DD (2006) A trait-based test for habitat filtering: convex hull volume. Ecology, 87, 14651471.

Costanza R, dArge R, deGroot $R$ et al. (1997) The value of the world's ecosystem services and natural capital. Nature, 387, 253-260.

Craine JM, Tilman D, Wedin D et al. (2002) Functional traits, productivity and effects on nitrogen cycling of 33 grassland species. Functional Ecology, 16, 563-574.

Currie DJ (2001) Projected effects of climate change on patterns of vertebrate and tree species richness in the conterminous United States. Ecosystems, 4, 216-225.

Daehler CC, Goergen EM (2005) Experimental restoration of an indigenous Hawaiian grassland after invasion by Buffel grass (Cenchrus ciliaris). Restoration Ecology, 13, 380-389.

D'Antonio CM, Kark S (2002) Impacts and extent of biotic invasions in terrestrial ecosystems. Trends in Ecology \& Evolution, 17, 202-204.

D'Antonio CM, Tunison JT, Loh RK (2000) Variation in the impact of exotic grasses on native plant composition in relation to fire across an elevation gradient in Hawaii. Austral Ecology, 25, 507-522. 
D'Antonio CM, Vitousek PM (1992) Biological invasions by exotic grasses, the grass fire cycle, and global change. Annual Review of Ecology and Systematics, 23, 63-87.

Davies KF, Margules CR, Lawrence KF (2000) Which traits of species predict population declines in experimental forest fragments? Ecology, 81, 1450-1461.

De Bello F, Leps J, Sebastia MT (2005) Predictive value of plant traits to grazing along a climatic gradient in the Mediterranean. Journal of Applied Ecology, 42, 824-833.

Díaz S (1995) Elevated $\mathrm{CO}_{2}$ responsiveness, interactions at the community level and plant functional types. Journal of Biogeography, 22, 289-295.

Díaz S, Cabido M (1997) Plant functional types and ecosystem function in relation to global change. Journal of Vegetation Science, 8, 463-474.

Díaz S, Cabido M (2001) Vive la difference: plant functional diversity matters to ecosystem processes. Trends in Ecology $\mathcal{E}$ Evolution, 16, 646-655.

Díaz S, Fraser LH, Grime JP, Falczuk V (1998) The impact of elevated $\mathrm{CO}_{2}$ on plant-herbivore interactions: experimental evidence of moderating effects at the community level. Oecologia, 117, 177-186.

Díaz S, Hodgson JG, Thompson K et al. (2004) The plant traits that drive ecosystems: evidence from three continents. Journal of Vegetation Science, 15, 295-304.

Díaz S, Lavorel S, McIntyre S et al. (2007) Plant trait responses to grazing - a global synthesis. Global Change Biology, 13, 313341.

Díaz S, Noy-Meir I, Cabido M et al. (2001) Can grazing response of herbaceous plants be predicted from simple vegetative traits? Journal of Applied Ecology, 38, 497-508.

Díaz S, Symstad AJ, Chapin FS et al. (2003) Functional diversity revealed by removal experiments. Trends in Ecology \& Evolution, 18, 140-146.

Elmqvist T, Folke C, Nystrom M, Peterson G, Bengtsson J, Walker B, Norberg J (2003) Response diversity, ecosystem change, and resilience. Frontiers in Ecology and the Environment, 1, 488-494.

Engelhardt KAM (2006) Relating effect and response traits in submerged aquatic macrophytes. Ecological Applications, 16, 1808-1820.

Epstein HE, Calef MP, Walker MD, Chapin FS, Starfield AM (2004) Detecting changes in arctic tundra plant communities in response to warming over decadal time scales. Global Change Biology, 10, 1325-1334.

Fargione J, Brown CS, Tilman D (2003) Community assembly and invasion: an experimental test of neutral versus niche processes. Proceedings of the National Academy of Sciences of the United States of America, 100, 8916-8920.

Farquhar GD, Sharkey TD (1982) Stomatal conductance and photosynthesis. Annual Review of Plant Physiology and Plant Molecular Biology, 33, 317-345.

Field CB, Chapin FS, Matson PA, Mooney HA (1992) Responses of terrestrial ecosystems to the changing atmosphere - a resource-based approach. Annual Review of Ecology and Systematics, 23, 201-235.

Forys EA, Allen CR (2002) Functional group change within and across scales following invasions and extinctions in the everglades ecosystem. Ecosystems, 5, 339-347.
Fraser LH, Grime JP (1999) Interacting effects of herbivory and fertility on a synthesized plant community. Journal of Ecology, 87, 514-525.

Gamarra JGP, Montoya JM, Alonso D, Sole RV (2005) Competition and introduction regime shape exotic bird communities in Hawaii. Biological Invasions, 7, 297-307.

Garnier E, Cortez J, Billes G et al. (2004) Plant functional markers capture ecosystem properties during secondary succession. Ecology, 85, 2630-2637.

Gitay H, Noble IR (1997) What are functional types and how should we seek them? In: Plant Functional Types: Their Relevance to Ecosystem Properties and Global Change (eds Smith TM, Shugart HH, Woodward FI), pp. 3-19. Cambridge University Press, Cambridge, UK.

Goldberg DE (1990) Components of resource competition in plant communities. In: Perspectives in Plant Competition (eds Grace J, Tilman D), pp. 27-49. Academic Press, San Diego, CA.

Goldberg DE (1996) Competitive ability: definitions, contingency and correlated traits. Philosophical Transactions of the Royal Society of London Series B-Biological Sciences, 351, 1377-1385.

Goldberg DE, Werner PA (1983) Equivalence of competitors in plant-communities - a null hypothesis and a field experimental approach. American Journal of Botany, 70, 1098-1104.

Gray ST, Betancourt JL, Jackson ST, Eddy RG (2006) Role of multidecadal climate variability in a range extension of pinyon pine. Ecology, 87, 1124-1130.

Grime JP (1998) Benefits of plant diversity to ecosystems: immediate, filter and founder effects. Journal of Ecology, 86, 902910.

Grime JP (2006) Trait convergence and trait divergence in herbaceous plant communities: mechanisms and consequences. Journal of Vegetation Science, 17, 255-260.

Grime JP, Brown VK, Thompson K et al. (2000) The response of two contrasting limestone grasslands to simulated climate change. Science, 289, 762-765.

Grime JP, Hodgson JG, Hunt R (1988) Comparative Plant Ecology: A Functional Approach to Common British Species. Unwin Hyman, London.

Grime JP, Thompson K, Hunt R et al. (1997) Integrated screening validates primary axes of specialisation in plants. Oikos, 79, 259-281.

Grimshaw HM, Allen SE (1987) Aspects of the mineral-nutrition of some native British plants - inter-site variation. Vegetatio, 70, 157-169.

Groffman P, Baron J, Blett T et al. (2006) Ecological thresholds: the key to successful environmental management or an important concept with no practical application? Ecosystems, 9, 1-13.

Grotkopp E, Rejmanek M, Rost TL (2002) Toward a causal explanation of plant invasiveness: seedling growth and lifehistory strategies of 29 pine (Pinus) species. American Naturalist, 159, 396-419.

Hamilton MA, Murray BR, Cadotte MW, Hose GC, Baker AC, Harris CJ, Licari D (2005) Life-history correlates of plant invasiveness at regional and continental scales. Ecology Letters, 8, 1066-1074.

Henry HAL, Cleland EE, Field CB, Vitousek PM (2005) Interactive effects of elevated $\mathrm{CO}_{2}, \mathrm{~N}$ deposition and climate 
change on plant litter quality in a California annual grassland. Oecologia, 142, 465-473.

Higgins SI, Lavorel S, Revilla E (2003) Estimating plant migration rates under habitat loss and fragmentation. Oikos, 101, 354-366.

Hobbie SE (1992) Effects of plant-species on nutrient cycling. Trends in Ecology \& Evolution, 7, 336-339.

Hobbie SE, Chapin FS (1998) Response of tundra plant biomass, aboveground production, nitrogen, and $\mathrm{CO}_{2}$ flux to experimental warming. Ecology, 79, 1526-1544.

Hobbs RJ, Mooney HA (1985) Community and populationdynamics of serpentine grassland annuals in relation to gopher disturbance. Oecologia, 67, 342-351.

Hobbs RJ, Mooney HA (1991) Effects of rainfall variability and gopher disturbance on serpentine annual grassland dynamics. Ecology, 72, 59-68.

Hooper DU, Chapin FS, Ewel JJ et al. (2005) Effects of biodiversity on ecosystem functioning: a consensus of current knowledge and needs for future research. Ecological Monographs, 75, 3-35.

Hooper DU, Johnson L (1999) Nitrogen limitation in dryland ecosystems: responses to geographical and temporal variation in precipitation. Biogeochemistry, 46, 247-293.

Hooper DU, Solan M, Symstad AJ et al. (2002) Species diversity, functional diversity, and ecosystem functioning. In: Biodiversity and Ecosystem Functioning: Synthesis and Perspectives (eds Loreau M, Naeem S, Inchausti P), pp. 195-208. Oxford University Press, Oxford.

Hubbell SP (2001) The Unified Neutral Theory of Biodiversity and Biogeography. Princeton University Press, Princeton, USA.

Iverson LR, Prasad AM (2001) Potential changes in tree species richness and forest community types following climate change. Ecosystems, 4, 186-199.

Jackson ST, Overpeck JT (2000) Responses of plant populations and communities to environmental changes of the late Quaternary. Paleobiology, 26, 194-220.

Jenkins DG, Buikema AL (1998) Do similar communities develop in similar sites? A test with zooplankton structure and function. Ecological Monographs, 68, 421-443.

Joel G, Chapin FS, Chiariello NR, Thayer SS, Field CB (2001) Species-specific responses of plant communities to altered carbon and nutrient availability. Global Change Biology, 7, 435-450.

Johnstone JF, Chapin FS (2003) Non-equilibrium succession dynamics indicate continued northern migration of lodgepole pine. Global Change Biology, 9, 1401-1409.

Jonsson M, Dangles O, Malmqvist B, Guerold F (2002) Simulating species loss following perturbation: assessing the effects on process rates. Proceedings of the Royal Society of London Series BBiological Sciences, 269, 1047-1052.

Klanderud K (2005) Climate change effects on species interactions in an alpine plant community. Journal of Ecology, 93, 127-137.

Knapp AK, Smith MD (2001) Variation among biomes in temporal dynamics of aboveground primary production. Science, 291, 481-484.

Kneitel JM, Miller TE (2003) Dispersal rates affect species composition in metacommunities of Sarracenia purpurea inquilines. American Naturalist, 162, 165-171.
Korner C (2000) Biosphere responses to $\mathrm{CO}_{2}$ enrichment. Ecological Applications, 10, 1590-1619.

Kremen C (2005) Managing ecosystem services: what do we need to know about their ecology? Ecology Letters, 8, 468-479.

Lambrinos JG (2002) The variable invasive success of Cortaderia species in a complex landscape. Ecology, 83, 518-529.

Landsberg J, Lavorel S, Stol J (1999) Grazing response groups among understorey plants in arid rangelands. Journal of Vegetation Science, 10, 683-696.

Larsen TH, Williams NM, Kremen C (2005) Extinction order and altered community structure rapidly disrupt ecosystem functioning. Ecology Letters, 8, 538-547.

Lauenroth WK, Sala OE (1992) Long-term forage production of North-American shortgrass steppe. Ecological Applications, 2, 397-403.

Lavorel S, Garnier E (2002) Predicting changes in community composition and ecosystem functioning from plant traits: revisiting the Holy Grail. Functional Ecology, 16, 545-556.

Lavorel S, McIntyre S, Landsberg J et al. (1997) Plant functional classifications: from general groups to specific groups based on response to disturbance. Trends in Ecology \& Evolution, 12, 474-478.

Leadley PW, Niklaus PA, Stocker R, Korner C (1999) A field study of the effects of elevated $\mathrm{CO}_{2}$ on plant biomass and community structure in a calcareous grassland. Oecologia, 118, 39-49.

Lee TD, Reich PB, Tjoelker MG (2003) Legume presence increases photosynthesis and $\mathrm{N}$ concentrations of co-occurring non-fixers but does not modulate their responsiveness to carbon dioxide enrichment. Oecologia, 137, 22-31.

Levine JM, Vila M, D'Antonio CM, Dukes JS, Grigulis K, Lavorel S (2003) Mechanisms underlying the impacts of exotic plant invasions. Proceedings of the Royal Society of London Series BBiological Sciences, 270, 775-781.

Lill JT, Marquis RJ (2003) Ecosystem engineering by caterpillars increases insect herbivore diversity on white oak. Ecology, 84, 682-690.

Lyford ME, Jackson ST, Betancourt JL, Gray ST (2003) Influence of landscape structure and climate variability on a late Holocene plant migration. Ecological Monographs, 73, 567-583.

Lyons KG, Brigham CA, Traut BH, Schwartz MW (2005) Rare species and ecosystem functioning. Conservation Biology, 19, 1019-1024.

Manning P, Newington JE, Robson HR et al. (2006) Decoupling the direct and indirect effects of nitrogen deposition on ecosystem function. Ecology Letters, 9, 1015-1024.

Mayer AL, Rietkerk M (2004) The dynamic regime concept for ecosystem management and restoration. Bioscience, 54, 10131020.

McGill BJ, Enquist BJ, Weiher E, Westoby M (2006) Rebuilding community ecology from functional traits. Trends in Ecology $\mathcal{E}$ Evolution, 21, 178-185.

McIntyre S, Lavorel S, Tremont RM (1995) Plant life-history attributes - their relationship to disturbance responses in herbaceous vegetation. Journal of Ecology, 83, 31-44.

Millennium Ecosystem Assessment (2003) Ecosystem Studies: Ecosystem Science and Management. Island Press, Washington, DC. 
Mondor EB, Tremblay MN, Awmack CS, Lindroth RL (2005) Altered genotypic and phenotypic frequencies of aphid populations under enriched $\mathrm{CO}_{2}$ and $\mathrm{O}_{3}$ atmospheres. Global Change Biology, 11, 1990-1996.

Morris WF, Hufbauer RA, Agrawal AA et al. (2007) Direct and interactive effects of enemies and mutualists on plant performance: a meta-analysis. Ecology, 88, 1021-1029.

Mouillot D, Stubbs W, Faure M et al. (2005) Niche overlap estimates based on quantitative functional traits: a new family of non-parametric indices. Oecologia, 145, 345-353.

Naeem S, Wright JP (2003) Disentangling biodiversity effects on ecosystem functioning: deriving solutions to a seemingly insurmountable problem. Ecology Letters, 6, 567-579.

Neilson RP, Pitelka LF, Solomon AM et al. (2005) Forecasting regional to global plant migration in response to climate change. Bioscience, 55, 749-759.

Noble IR, Gitay H (1996) A functional classification for predicting the dynamics of landscapes. Journal of Vegetation Science, 7, 329-336.

Nystrom M (2006) Redundancy and response diversity of functional groups: implications for the resilience of coral reefs. Ambio, 35, 30-35.

Oesterheld M (1992) Effect of defoliation intensity on aboveground and belowground relative growth-rates. Oecologia, 92, 313-316.

Olden JD, Poff NL, Bestgen KR (2006) Life-history strategies predict fish invasions and extirpations in the Colorado River Basin. Ecological Monographs, 76, 25-40.

Osmond B, Ananyev G, Berry J et al. (2004) Changing the way we think about global change research: scaling up in experimental ecosystem science. Global Change Biology, 10, 393-407.

Pennings SC, Siska EL, Bertness MD (2001) Latitudinal differences in plant palatability in Atlantic coast salt marshes. Ecology, 82, 1344-1359.

Petchey OL, Gaston KJ (2002) Extinction and the loss of functional diversity. Proceedings of the Royal Society of London Series B-Biological Sciences, 269, 1721-1727.

Petchey OL, Gaston KJ (2006) Functional diversity: back to basics and looking forward. Ecology Letters, 9, 741-758.

Poff NL (1997) Landscape filters and species traits: towards mechanistic understanding and prediction in stream ecology. Journal of the North American Benthological Society, 16, 391-409.

Poorter H, Navas ML (2003) Plant growth and competition at elevated $\mathrm{CO}_{2}$ : on winners, losers and functional groups. New Phytologist, 157, 175-198.

Power ME, Tilman D, Estes JA et al. (1996) Challenges in the quest for keystones. Bioscience, 46, 609-620.

Pugnaire FI, Luque MT (2001) Changes in plant interactions along a gradient of environmental stress. Oikos, 93, 42-49.

Purvis A, Gittleman JL, Cowlishaw G, Mace GM (2000) Predicting extinction risk in declining species. Proceedings of the Royal Society of London Series B-Biological Sciences, 267, 1947-1952.

Quested H, Eriksson O (2006) Litter species composition influences the performance of seedlings of grassland herbs. Functional Ecology, 20, 522-532.

Quétier F, Thebault A, Lavorel S (2007) Plant traits in a state and transition framework as markers of ecosystem response to land-use change. Ecological Monographs, 77, 33-52.
Rehfeldt GE, Ying CC, Spittlehouse DL, Hamilton DA (1999) Genetic responses to climate in Pinus contorta: niche breadth, climate change, and reforestation. Ecological Monographs, 69, 375-407.

Reich PB, Tilman D, Craine J et al. (2001) Do species and functional groups differ in acquisition and use of $\mathrm{C}, \mathrm{N}$ and water under varying atmospheric $\mathrm{CO}_{2}$ and $\mathrm{N}$ availability regimes? A field test with 16 grassland species. New Phytologist, 150, 435-448.

Reich PB, Walters MB, Ellsworth DS (1997) From tropics to tundra: global convergence in plant functioning. Proceedings of the National Academy of Sciences of the United States of America, 94, 13730-13734.

Reich PB, Wright IJ, Cavender-Bares J, Craine JM, Oleksyn J, Westoby M, Walters MB (2003) The evolution of plant functional variation: traits, spectra, and strategies. International Journal of Plant Sciences, 164, S143-S164.

Schiesari L, Peacor S, Werner EE (2006) The growth-mortality tradeoff: evidence from anuran larvae and consequences for species distributions. Oecologia, 149, 194-202.

Schmitz OJ (2004) Perturbation and abrupt shift in trophic control of biodiversity and productivity. Ecology Letters, 7, 403-409.

Schmitz OJ, Post E, Burns CE, Johnston KM (2003) Ecosystem responses to global climate change: moving beyond color mapping. Bioscience, 53, 1199-1205.

Schulze ED, Kelliher FM, Korner C, Lloyd J, Leuning R (1994) Relationships among maximum stomatal conductance, ecosystem surface conductance, carbon assimilation rate, and plant nitrogen nutrition - a global ecology scaling exercise. Annual Review of Ecology and Systematics, 25, 629-666.

Shaver GR, Canadell J, Chapin FS et al. (2000) Global warming and terrestrial ecosystems: a conceptual framework for analysis. Bioscience, 50, 871-882.

Smith MD, Wilcox JC, Kelly T, Knapp AK (2004) Dominance not richness determines invasibility of tallgrass prairie. Oikos, 106, 253-262.

Solan M, Cardinale BJ, Downing AL, Engelhardt KAM, Ruesink JL, Srivastava DS (2004) Extinction and ecosystem function in the marine benthos. Science, 306, 1177-1180.

Steffen W, Sanderson A, Tyson PD et al. (eds) (2004) Global Change and the Earth System: A Planet Under Pressure. Springer-Verlag, Berlin.

Sugihara G, Bersier LF, Southwood TRE, Pimm SL, May RM (2003) Predicted correspondence between species abundances and dendrograms of niche similarities. Proceedings of the $\mathrm{Na}$ tional Academy of Sciences of the United States of America, 100, 5246-5251.

Swetnam TW, Betancourt JL (1998) Mesoscale disturbance and ecological response to decadal climatic variability in the American Southwest. Journal of Climate, 11, 3128-3147.

Symstad AJ, Chapin FS, Wall DH et al. (2003) Long-term and large-scale perspectives on the relationship between biodiversity and ecosystem functioning. Bioscience, 53, 89-98.

Thomas CD, Cameron A, Green RE et al. (2004) Extinction risk from climate change. Nature, 427, 145-148.

Thompson JN, Reichman OJ, Morin PJ et al. (2001) Frontiers of ecology. Bioscience, 51, 15-24. 
Tilman D (1982) Resource Competition and Community Structure. Princeton University Press, Princeton, USA.

van der Putten WH, de Ruiter PC, Bezemer TM, Harvey JA, Wassen M, Wolters V (2004) Trophic interactions in a changing world. Basic and Applied Ecology, 5, 487-494.

van Nes EH, Scheffer M (2004) Large species shifts triggered by small forces. American Naturalist, 164, 255-266.

Vitousek PM, Hattenschwiler S, Olander L, Allison S (2002) Nitrogen and nature. Ambio, 31, 97-101.

Waide RB, Willig MR, Steiner CF et al. (1999) The relationship between productivity and species richness. Annual Review of Ecology and Systematics, 30, 257-300.

Walker B, Kinzig A, Langridge J (1999) Plant attribute diversity, resilience, and ecosystem function: the nature and significance of dominant and minor species. Ecosystems, 2, 95-113.

Wardle DA, Bardgett RD, Klironomos JN, Setala H, van der Putten WH, Wall DH (2004) Ecological linkages between aboveground and belowground biota. Science, 304, 1629-1633.

Wardle DA, Nilsson MC, Zackrisson O, Gallet C (2003a) Determinants of litter mixing effects in a Swedish boreal forest. Soil Biology \& Biochemistry, 35, 827-835.

Wardle DA, Peltzer DA (2003) Interspecific interactions and biomass allocation among grassland plant species. Oikos, 100, 497-506.

Wardle DA, Yeates GW, Williamson W, Bonner KI (2003b) The response of a three trophic level soil food web to the identity and diversity of plant species and functional groups. Oikos, 102, 45-56.

Weiher E, Clarke GDP, Keddy PA (1998) Community assembly rules, morphological dispersion, and the coexistence of plant species. Oikos, 81, 309-322.

Weiher E, van der Werf A, Thompson K et al. (1999) Challenging Theophrastus: a common core list of plant traits for functional ecology. Journal of Vegetation Science, 10, 609-620.

Whitham TG, Young WP, Martinsen GD et al. (2003) Community and ecosystem genetics: a consequence of the extended phenotype. Ecology, 84, 559-573.
Williams JW, Jackson ST, Kutzbach JE (2007) Projected distributions of novel and disappearing climates by 2100 AD. Proceedings of the National Academy of Sciences, 104, 57385742.

Williams NSG, Morgan JW, McDonnell MJ, McCarthy MA (2005) Plant traits and local extinctions in natural grasslands along an urban-rural gradient. Journal of Ecology, 93, 1203-1213.

Wilson SD, Tilman D (1993) Plant competition and resource availability in response to disturbance and fertilization. Ecology, 74, 599-611.

Wilson SD, Tilman D (2002) Quadratic variation in old-field species richness along gradients of disturbance and nitrogen. Ecology, 83, 492-504.

Wolters V, Silver WL, Bignell DE et al. (2000) Effects of global changes on above- and belowground biodiversity in terrestrial ecosystems: implications for ecosystem functioning. Bioscience, 50, 1089-1098.

Woodward FI (1992) Predicting plant-responses to global environmental-change. New Phytologist, 122, 239-251.

Woodward FI, Diament AD (1991) Functional approaches to predicting the ecological effects of global change. Functional Ecology, 5, 202-212.

Woodward FI, Thompson GB, McKee IF (1991) The effects of elevated concentrations of carbon-dioxide on individual plants, populations, communities and ecosystems. Annals of Botany, 67, 23-38.

Wootton JT (2002) Mechanisms of successional dynamics: consumers and the rise and fall of species dominance. Ecological Research, 17, 249-260.

Wright IJ, Reich PB, Westoby M et al. (2004) The worldwide leaf economics spectrum. Nature, 428, 821-827.

Wright JP, Jones CG (2004) Predicting effects of ecosystem engineers on patch-scale species richness from primary productivity. Ecology, 85, 2071-2081.

Wright JP, Naeem S, Hector A et al. (2006) Conventional functional classification schemes underestimate the relationship with ecosystem functioning. Ecology Letters, 9, 111-120. 